\title{
Working posture analysis of construction
}

\author{
workers using ergonomics.
}

\section{Análisis de la postura de trabajo de la construcción. trabajadores que utilizan la ergonomía.}

\author{
Anagha. $\mathrm{R}^{1}$, Annie Sonia Xavier ${ }^{2}$ \\ Department of Civil Engineering Toc $\mathrm{H}$ Institute of Science And Technology, Kerala, India \\ 1 PG Student (email: anagharajasekharan95@gmail.com), 2 Assistant Professor, (email: \\ anniesonia@tistcochin.edu.in)
}

\begin{abstract}
Ergonomics integrates knowledge from the human sciences to match jobs, systems, products, and environments to the physical and mental abilities and limitations of people. Most of the injuries, stresses and strains in construction industry occur due to over-exertion and repetitive work actions. Postural analysis can be a powerful technique for assessing work activities. Use of ergonomic principles reduces fatigue experienced by the human body in various tasks. Ergonomics deals with the study of internal and external stresses acting on the human body. The aim of this study is to assess the level of ergonomics in various tasks in the construction industry. The study also aims to find the level of musculoskeletal disorders in workers and suggest corrective measures for every task having high risk factor. The study is conducted by using the Rapid Entire Body Assessment (REBA) tool of Ergofellow software, to assess the posture of workers in various construction tasks. Fatigue analysis is done by this method, which provides a scoring system for muscle activity caused by static, dynamic, rapid changing or unstable postures.
\end{abstract} Keywords: Ergonomics, REBA, Musculoskeletal Disorders.

\section{RESUMEN}

La ergonomía integra el conocimiento de las ciencias humanas para hacer coincidir los trabajos, sistemas, productos y entornos con las capacidades y limitaciones físicas y mentales de las personas. La mayoría de las lesiones, tensiones y tensiones en la industria de la construcción ocurren debido al esfuerzo excesivo y las acciones de trabajo repetitivas. El análisis postural puede ser una técnica poderosa para evaluar las actividades laborales. El uso de principios ergonómicos reduce la fatiga experimentada por el cuerpo humano en diversas tareas. La ergonomía se ocupa del estudio de las tensiones internas y externas que actúan sobre el cuerpo humano. El objetivo de este estudio es evaluar el nivel de ergonomía en diversas tareas de la industria de la construcción. El estudio también tiene como objetivo conocer el nivel de trastornos musculoesqueléticos en los trabajadores 
Sustainability, Agri, Food and Environmental Research, (ISSN: 0719-3726), 10(X), 2022: http://dx.doi.org/

y sugerir medidas correctivas para cada tarea que tenga un factor de alto riesgo. El estudio se lleva a cabo utilizando la herramienta de evaluación rápida de todo el cuerpo (REBA) del software Ergofellow, para evaluar la postura de los trabajadores en diversas tareas de construcción. El análisis de la fatiga se realiza mediante este método, que proporciona un sistema de puntuación para la actividad muscular causada por posturas estáticas, dinámicas, de cambio rápido o inestables.

Palabras clave: Ergonomía, REBA, Trastornos musculoesqueléticos

\section{INTRODUCTION}

Construction industry is one of the most booming industries in the world. An integral part of this industry is the workers. Construction workers are those, who perceive more clearly the lack of job safety. It has been evidenced by a number of studies that construction industry is one of the most hazardous work place industries with high rates of fatalities, injuries and health problems. The high levels of ill-health, accidents and injuries among construction workers could be explained by a high variety of risk factors on the job. This can be assessed by applying ergonomics in construction industry. Ergonomics is the science of fitting the job to the worker. It deals with the study of internal and external stresses acting on the human body. Use of ergonomic principles reduces fatigue experienced by the human body in various tasks.

\section{SCOPE OF THE STUDY}

- The study is limited to five construction tasks involving high potential of development of musculoskeletal disorder (MSD).

- Construction workers with a minimum of 5 years of experience are analysed.

- Workers from commercial and residential multi-storey building sites are considered.

- Continuous monitoring of workers is beyond the scope of this study.

\section{LITERATURE REVIEW}

From the literature review it is noted that Rapid Upper Limb Assessment, RULA and Rapid Entire Body Assessment, REBA are two of the important postural analysis tools [Ansari N A and Dr. Sheikh M J (2014)], [Bhandare A, Bahirat P, Nagarkar V, and Bewoor A (2013)]. RULA provides a quick assessment of the postures of the neck, trunk and upperlimbs along with muscle function and the external loads experienced by the body [McAtamney L and Corlett E N (1993)]. REBA is an analytical tool for entire body assessment [Hignet S, and McAtamney L (2000)].The fatigue involved in particular operations can be quantified and accordingly changes in the work method for system improvement can be suggested with these methods. Some of the other tools for postural analysis are OWAS, RII and PATH methods [Chiasson M, Imbeau D, Aubry K and Delisle A 
Sustainability, Agri, Food and Environmental Research, (ISSN: 0719-3726), 10(X), 2022: http://dx.doi.org/

(2012)], [Kong Y, Lee S, Lee K and Kim D (2017)], [Kulkarni V S and Devalkar R V (2017)], [Kulkarni V S and Devalkar R V (2018)]. From studies it was observed that the analysis done by RULA and REBA were more consistent and correlated.Most of the studies on postural analysis was conducted in farming, production and manufacturing industries. The postural analysis conducted in construction sites were only for a limited set of activities like excavation, plastering and brickwork. From literature survey it was observed that for the efficient and accurate capturing of postures mobile applications can be an effective and economic tool [Szucs K A and Brown E D (2018)]. So, a mobile application called 'APECS' is adopted for the posture capture and validation. Since the postural analysis of a large dataset of workers is a tedious task, REBA method from ergonomic software called 'Ergofellow' is adopted, because REBA provides more consistent and correlated results compared to other methods. From previous studies and literature reviews the construction activities, having a potential of MSD, selected for this particular study are; reinforcement work, plastering, shuttering, concrete block work and manual material handling.

\section{DATA COLLECTION}

Data for the analysis comprises of results of questionnaires and checklist along with a set of photos or video sequences. This is collected using a portable camera or a video camera. This method of data collection is preferred because it does not interfere with the work flow at the site. Since images from multiple frames and angles are captured, it provides better accuracy. It also acts as a record for future reference.

Posture Capture and Validation Using APECS-APECS stands for AI Posture Evaluation and Correction System. It is a posture analyzer for accurate evaluation of spine alignment and body symmetry. It is educational software developed by the company New Body Technology. The software used for this study is the version 2.2.7, for android operating systems. It uses precise photogrammetric algorithms to make accurate posture assessments. A sample image of a concrete block worker captured using APECS is shown in fig.1. Body lines and their respective angles can be read directly from the image. 


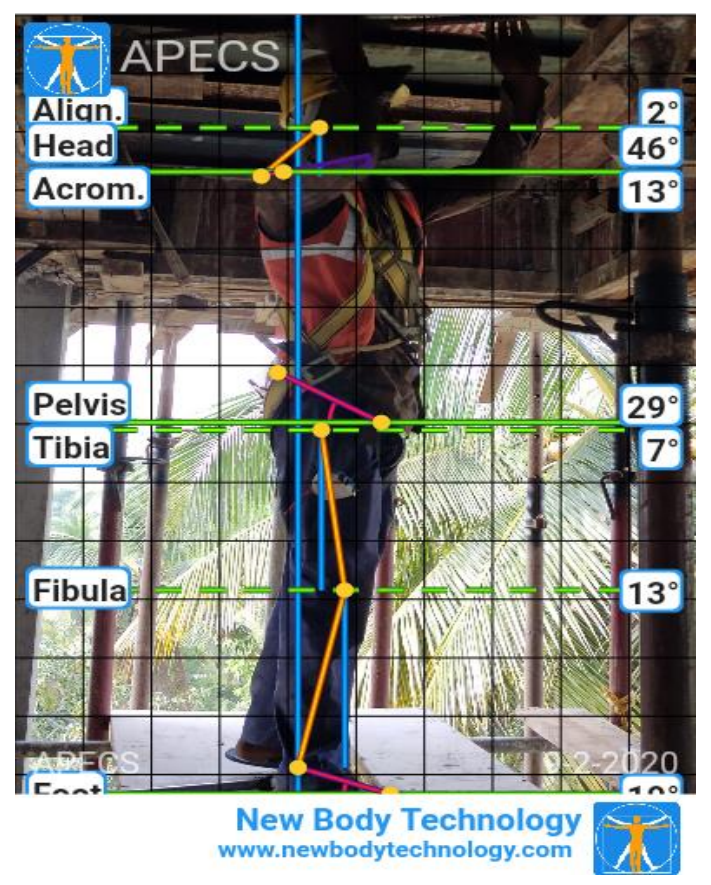

Fig.1. Sample image of a construction worker captured using APECS (Source: By author)

Postural Analysis Using Ergofellow Software- Ergofellow is a software package developed by FBF Systemas. It consists of 17 ergonomic tools in order to reduce occupational risks and increase productivity. The REBA tool of this software package is adopted here for analysis of working posture of construction workers. Once the image is captured accurately, all the body angles and other necessary data are filled into the REBA tool of the Ergofellow software. Analysis of the worker in fig.1.is done here. The angles of body parts neck, trunk and legs are to be provided first as shown in fig. 2 . Additional data like any twisting or bending of the neck and trunk, and the support conditions are also filled. Similarly, load factors are filled from the given options. The load is divided into three categories as less than $5 \mathrm{~kg}, 5$ to $10 \mathrm{~kg}$ and greater than 10 $\mathrm{kg}$. Additional provision in case of shock or rapid build up force can also be specified. Next step is to specify the body angles of upper arm, lower arm and wrist, as shown in fig.3.Additional provisions for each body part is also available. The coupling factors are to be filled next. These are to measure and score the hand hold and grip of the tools used for the work. Poor and unacceptable coupling conditions will increase the strain in wrist and lower limbs. The last option to be filled is the activity. i.e., whether the body parts are held static for longer than a minute, any repeated actions or any large range changes in posture. Once all the body angles and the field conditions are specified the result is obtained from the software as shown in fig.4. The software produces the REBA score and shows the risk level. For this particular example of shuttering worker the 
Sustainability, Agri, Food and Environmental Research, (ISSN: 0719-3726), 10(X), 2022 : http://dx.doi.org/

score obtained is 7 which indicate medium risk. Therefore further investigations or change in posture can be adopted.

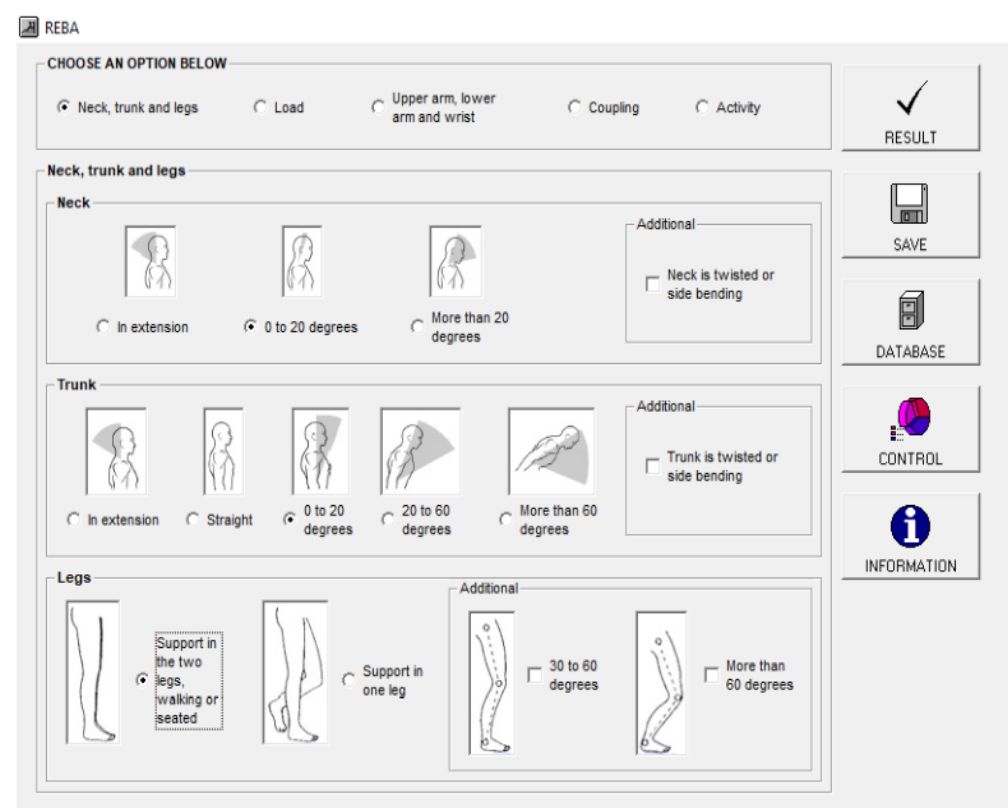

Fig.2. Specifying angles for neck, trunk and legs (Source: Ergofellow analysis) 团 REBA

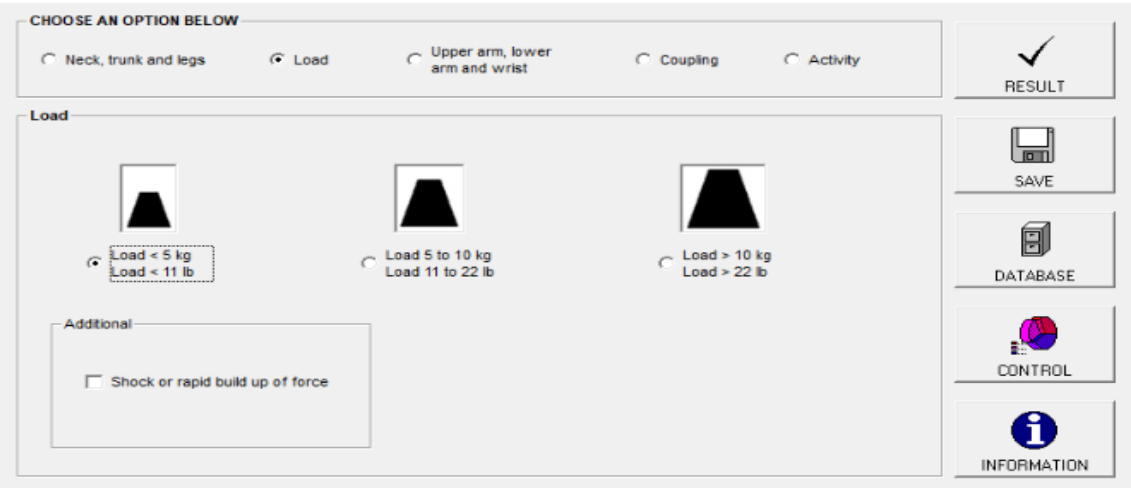

Fig.3. Specifying Loads (Source: Ergofellow analysis) 团 REBA

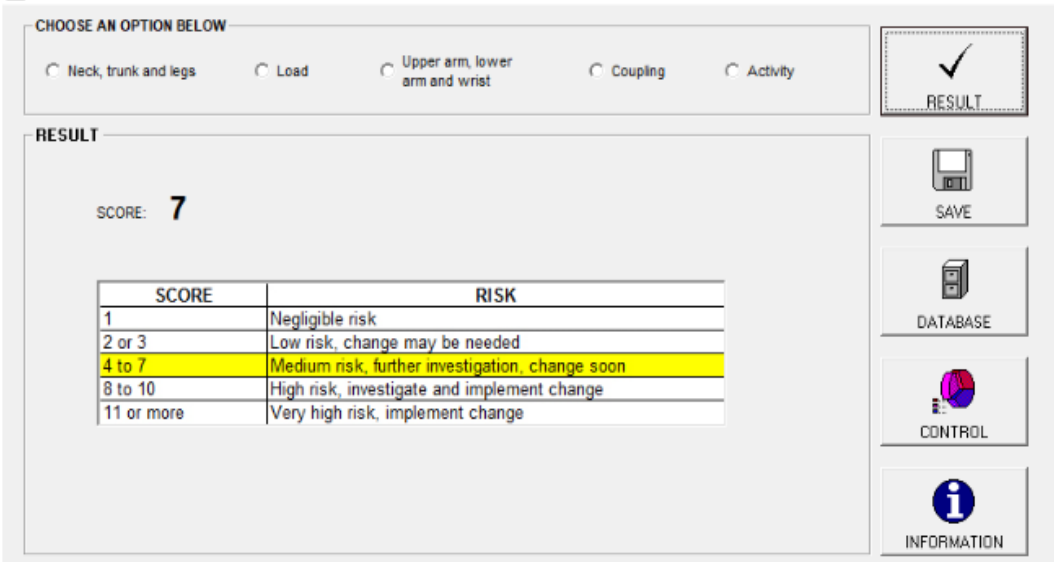

Fig.4. Final Result (Source: Ergofellow analysis) 
Ergofellow software allows the analysis of large datasets. These data can be filled into the database as per the category of the work. This software provides with category wise results of analysis in percentages and graphs. The results and graph for the shuttering workers are shown in fig.5. where the number of workers is shown on the $y$-axis and risk level is on the $\mathrm{x}$-axis of the result graph.

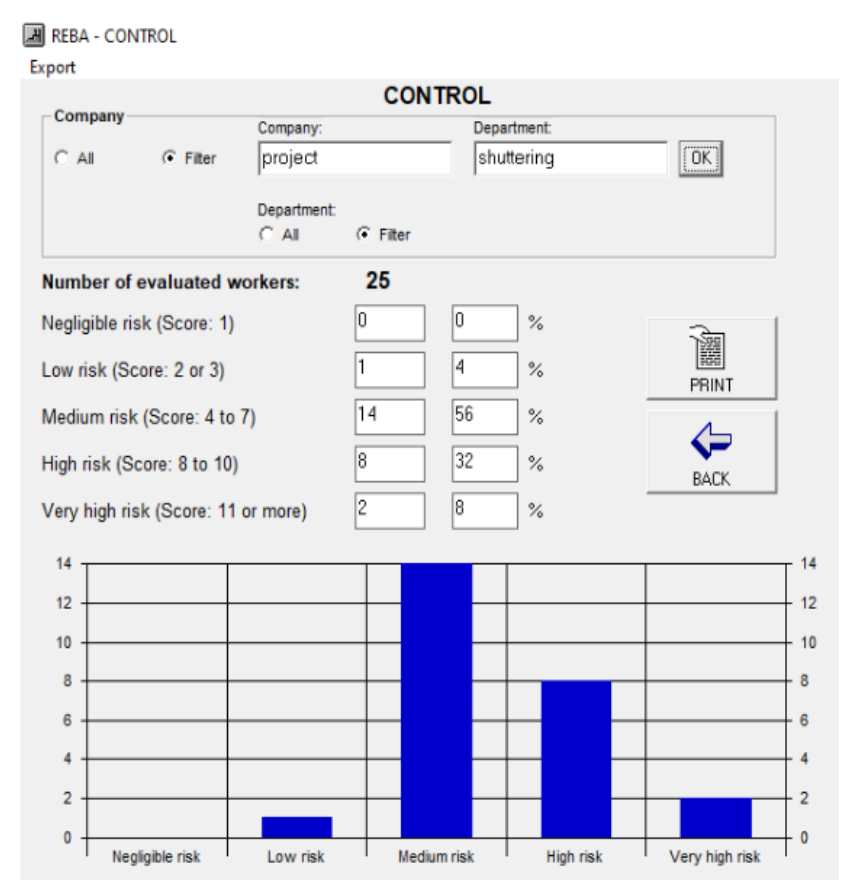

Fig.5.Results of shuttering workers

(Source: Ergofellow analysis)

\section{RESULTS AND DISCUSSIONS}

Data for 154 workers performing different construction activities were analysed using REBA tool of Ergofellow software. Construction workers performing reinforcement works were analysed for this work due to their high potential of MSD development. Strained areas observed in them were trunk, shoulders and neck. A total of 41 reinforcement workers were analysed out of which, 26 were at medium risk i.e., $63.41 \%$ with a score of 4 to 7 .Also, 13 workers were at high risk i.e. $31.7 \%$ with a score of 8 to 10 and 2 were at low risk i.e., $4.878 \%$ with a score of 2 or3.workers with negligible risk and very high risk were nil. Construction workers performing plastering works in both standing and seated positions were observed. From the 38 workers analysed, it was inferred that the major areas of strain were trunk shoulders and upper limbs. For those workers in seating position knee was also strained. Out of the 38 plastering workers analysed, 24 were at medium risk i.e., $63.15 \%$ with a score of 4 to 7.Also, 13 workers were at high risk i.e., $34.21 \%$ with a score of 8 to 10 and 1 was at very high risk i.e., $2.631 \%$ with a score of 11 .workers with negligible risk and low risk were nil. 
Sustainability, Agri, Food and Environmental Research, (ISSN: 0719-3726), 10(X), 2022:

http://dx.doi.org/

Among the shuttering workers observed main problem was their awkward posture, unstable base and lack of stable support mechanisms. Due to this, the major body parts strained weretrunk, neck, upper limbs and knee. A total of 25 shuttering workers were observed out of which, 14 were at medium risk i.e., $56 \%$ with a score of 4 to 7 .Also, 8 workers were at high risk i.e.32\% with a score of 8 to 10 two people were at very high risk i.e., $8 \%$ with a score of 11 and 1 was at low risk i.e., $4 \%$ with a score of 3 .workers with negligible risk were nil.Among concrete block workers the main problem observed was their frequent bending to reach materials, unstable base and work not performed at eye level. Due to this, the major body parts strained weretrunk, neck, upper limbs and shoulder. A total of 25 concrete block workers were observed out of which 11 were at medium risk i.e., $44 \%$ with a score of 4 to 7 .Also, 12 workers were at high risk i.e. $48 \%$ with a score of 8 to 10 . One worker was at very high risk i.e., $4 \%$ with a score of 11 and one was also at low risk i.e., $4 \%$ with a score of 3.workers with negligible risk were nil. Among the manual material handling workers observed, main problem was their incorrect hold of materials and poor lifting mechanisms. Due to this, the major body parts strained weretrunk, shoulders, upper limbs and knee. Weight of the construction material was also a contributing factor. It was inferred that out of the 25 manual material handling workers analysed, 8 were at medium risk i.e., $32 \%$ with a score of 4 to 7 .Also, 16 workers were at high risk i.e.64\% with a score of 8 to 10 .one worker was at low risk i.e., $4 \%$ with a score of 3and workers with negligible risk and very high risk were nil. The percentage results of construction workers performing each task is compiled into a tabular form as shown in table.1.

Table.1. Percentage results of construction workers

\begin{tabular}{|c|c|c|c|c|c|c|}
\hline Work & $\begin{array}{c}\text { Reinforcement } \\
\text { work }\end{array}$ & Plastering & Shuttering & $\begin{array}{c}\text { Concrete } \\
\text { block } \\
\text { work }\end{array}$ & $\begin{array}{c}\text { Manual } \\
\text { material } \\
\text { handling }\end{array}$ & $\begin{array}{c}\text { Total } \\
\text { Risk } \\
\text { (\%) }\end{array}$ \\
\hline $\begin{array}{c}\text { Negligible } \\
\text { risk (\%) }\end{array}$ & 0 & 0 & 0 & 0 & 0 & 0 \\
\hline $\begin{array}{c}\text { Low risk } \\
\text { (\%) }\end{array}$ & 4.878 & 0 & 4 & 4 & 4 & 3.24 \\
\hline $\begin{array}{c}\text { Medium } \\
\text { risk (\%) }\end{array}$ & 63.41 & 63.15 & 56 & 44 & 32 & 53.896 \\
\hline $\begin{array}{c}\text { High risk } \\
(\%)\end{array}$ & 31.71 & 34.21 & 32 & 48 & 64 & 40.25 \\
\hline $\begin{array}{c}\text { Very high } \\
\text { risk (\%) }\end{array}$ & 0 & 2.631 & 8 & 4 & 0 & 2.597 \\
\hline
\end{tabular}

\section{CONCLUSION}

REBA assessment identified that the shoulders, knees, legs and back were at a high risk for developing MSDs due to the abducted lower-body postures, the repeated actions and the flexion and extension of the upper limbs. It was also observed that along with incorrect 
Sustainability, Agri, Food and Environmental Research, (ISSN: 0719-3726), 10(X), 2022: http://dx.doi.org/

and awkward working posture, certain factors like poor coupling, unstable base, static postures and repetitive actions also contributed to these high risk levels. From a total of 154 workers analysed, most of them were under medium to high risk. From the results of the REBA assessment, it was observed that majority of the workers i.e., $53.896 \%$ of the total workers were under medium risk, $40.25 \%$ of the total workers were under high risk, $2.597 \%$ were under very high risk and $3.24 \%$ were under low risk. The outcomes indicate that there was a high risk of developing MSDs. The major reasons for this large percentage of high and medium risks can be concluded as awkward postures along with its duration and other external factors like poor coupling, excessive load and repeated actions under poor supervision. The process needs to be investigated further, and changes must be implemented to protect the workers.

\section{SUGGESTIONS AND RECOMMENDATIONS}

Majority of the reinforcement workers were at medium risk and a considerably large percentage were at high risk. This can be minimized up to a greater extend by avoiding static bending posture. Appropriate support mechanisms should be provided to the workers, which will reduce the stress in their legs and knees. The safety officer/ engineer should ensure correct working posture of the workers. A large percentage of plastering workers were at medium risk due to stretched neck, trunk and upper limbs. Use of stable elevated platforms for overhead plastering can reduce the strain in neck, shoulders and trunk. For plastering at lower levels, appropriate seating should be adopted to avoid strain on knee and lower limbs.Proper equipments like guniting tools should be used to aid plastering over a larger area.

Majority of the shuttering workers were at medium to high risk, the main cause of which was bend trunk and insufficient support. In order to reduce this strain, works should be done at appropriate heights. Also, usage of ladders in shuttering activities helps the worker to work at eye-level. Stable working platform and appropriate support mechanisms are the basic changes to be adopted to reduce unnecessary efforts of the worker. In the case of concrete block workers, majority of them were at high risk due to frequent bending and stretching to reach materials and tools. Immediate change in posture is recommended for such workers.An elevated platform for storage should be provided to keep the concrete blocks, mortar and other equipments.This helps to keep all the equipments within immediate reach and avoids unnecessary movements.

A high percentage of manual material handling workers were at high risk due to improper lifting techniques. The workers should be given proper training regarding the method of handling the construction materials. They should adopt postures that distribute the weight of the construction material equally to the body. Also, avoid lifting/carrying materials using one side of the body as it will strain that particular side of body and will also affect the 
Sustainability, Agri, Food and Environmental Research, (ISSN: 0719-3726), 10(X), 2022:

http://dx.doi.org/

trunk of the worker. Weight of the construction material was a contributing factor to the risk. Usage of equipments like trolleys can minimise these efforts.

\section{FUTURE SCOPE}

This study involves posture analysis of construction workers using REBA method. In future works other ergonomic tools and more sophisticated computer based applications may be adopted. The sample size can be taken in a wide range to improve the accuracy of the results. For this study, five particular tasks were only considered. This can be improved by incorporating all the construction tasks in a site for the study. Consideration of external factors like previous medical history of the workers, their physical features etc may also be adopted.

\section{REFERENCES}

Ansari N.A. and Dr. Sheikh M.J. 2014. Evaluation of work Posture by RULA and REBA: A Case Study, IOSR Journal of Mechanical and Civil Engineering 11: 18-23.

Bhandare A., Bahirat P., Nagarkar V., and Bewoor A., 2013. Postural Analysis And Quantification of Fatigue By Using RULA And REBA Techniques, International Journal of Mechanical and Production Engineering, 1(3), ISSN: 2320-2092.

Chiasson M., Imbeau D., Aubry K. and Delisle A. 2012. Comparing The Results Of Eight Methods Used To Evaluate Risk Factors Associated With Musculoskeletal Disorders, International Journal of Industrial Ergonomics $42,478-488$.

Hignet S., and McAtamney L. 2000. Rapid Entire Body Assessment (REBA), Applied Ergonomics, 31, 201-205.

Kong Y., Lee S., Lee K. and Kim D. 2017. Comparisons of Ergonomic Evaluation Tools (ALLA, RULA, REBA and OWAS) for Farm Work, International Journal of Occupational Safety and Ergonomics, 1080-3548.

Kulkarni V.S. and Devalkar R.V., 2017. Ergonomic Analysis of Postures of Building Construction Workers Using RII \& PATH Method, International Journal of Innovative Research in Science, Engineering and Technology, 6: 2347-6710.

Kulkarni V.S. and Devalkar R.V. 2018. Postural Analysis Of Building Construction Workers Using Ergonomics, International Journal of Construction Management, 1562-3599.

McAtamney L. and Corlett E.N. 1993. RULA: A Survey Method for the Investigation of Work-Related Upper Limb Disorders, Applied Ergonomics, 24: 91-99.

Szucs K.A. and Brown E.D. 2018. Rater reliability and construct validity of a mobile application for posture analysis, The Journal of Physical Therapy Science, 30, 3136.

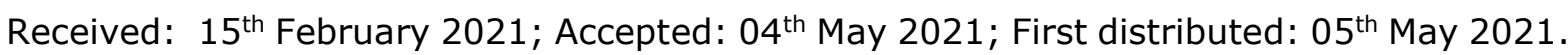

